\section{Visual and anatomical outcomes following intravitreal aflibercept in eyes with recalcitrant neovascular age-related macular degeneration: 12-month results}

DS Grewal, MK Gill, D Sarezky, AT Lyon and RG Mirza

\begin{abstract}
Purpose To describe the efficacy of intravitreal aflibercept on 12-month visual and anatomical outcomes in patients with neovascular age-related macular degeneration (AMD) recalcitrant to prior monthly intravitreal bevacizumab or ranibizumab. Methods Non-comparative case series of 21 eyes of 21 AMD patients with evidence of persistent exudation (intraretinal fluid/cysts, or subretinal fluid (SRF), or both) on spectral domain OCT despite $\geq 6$ prior intravitreal $0.5 \mathrm{mg}$ ranibizumab or $1.25 \mathrm{mg}$ bevacizumab (mean $29.8 \pm 17.1$ injections) over $31.6 \pm 17.4$ months who were transitioned to aflibercept. Results At baseline, best-corrected visual acuity (BCVA) was $0.42 \pm 0.28$ logarithm of minimum-angle of resolution ( $\log M A R)$, central foveal thickness (CFT) was $329.38 \pm 102.67 \mu \mathrm{m}$ and macular volume (MV) was $7.71 \pm 1.32 \mathrm{~mm}^{3}$. After 12 months of aflibercept (mean 10.2 \pm 1.2 injections), BCVA was $0.40 \pm 0.28 \log$ MAR $(P=0.5)$, CFT decreased to $292.71 \pm 91.35 \mu \mathrm{m}(P=0.038)$ and MV improved to $7.33 \pm 1.27 \mathrm{~mm}^{3}(P=0.003)$. In a subset of 15 eyes with a persistent fibrovascular or serous pigment epithelial detachment (PED), mean baseline PED greatest basal diameter (GBD) was $2350.9 \pm 1067.6 \mu \mathrm{m}$ and mean maximal height (MH) was $288.7 \pm 175.9 \mu \mathrm{m}$. At 12 months, GBD improved to $1896.3 \pm 782.3 \mu \mathrm{m}$ $(P=0.028)$, while MH decreased to $248.27 \pm 146.2 \mu \mathrm{m}(P=0.002)$.
\end{abstract}

Conclusion In patients with recalcitrant AMD, aflibercept led to anatomic improvement at $\mathbf{1 2}$ months, reduction in proportion of eyes with SRF and reduction in PED, while preserving visual acuity.

Eye (2014) 28, 895-899; doi:10.1038/eye.2014.101; published online 16 May 2014

\section{Introduction}

Some eyes with neovascular age-related macular degeneration (AMD) have persistent disease activity despite monthly therapy. ${ }^{1}$ Various strategies have been attempted in eyes including increasing the frequency of dosing ${ }^{2}$ by alternating treatment between ranibizumab and bevacizumab or increasing the dose of the drug while maintaining a monthly regimen. ${ }^{2}$

Efforts have also focused on switching these eyes to aflibercept. ${ }^{3-6}$

In this case series review, we analyze the visual and anatomical changes following 12 months of intravitreal aflibercept in previously treated patients with recalcitrant exudative-AMD.

Case series

This was an interventional, IRB approved, noncomparative case series of consecutive patients with neovascular AMD that were switched from treatment with intravitreal ranibizumab or bevacizumab to intravitreal aflibercept for recalcitrant exudative-AMD defined as
Department of Ophthalmology, Northwestern University Feinberg School of Medicine, Chicago, IL, USA

Correspondence: RG Mirza, Department of Ophthalmology, Northwestern University Feinberg School of Medicine, 645 North Michigan Avenue, Suite 440,Chicago, IL 60611, USA

Tel: +1 312908 8152;

Fax: +1 3125038152

E-mail: r-mirza@

northwestern.edu

Received: 13 October 2013 Accepted in revised form: 26 January 2014 Published online: 16 May 2014

Presented in part as a poster at the Association for Research in Vision and Ophthalmology Annual Meeting in May 2013 and the American Society of Retina Specialists Annual Meeting in August 2013 
choroidal neovascularization secondary to AMD with spectral domain OCT (SD-OCT; Heidelberg Spectralis HRA + OCT, Vista, CA, USA) documentation of subretinal fluid (SRF) and/or intraretinal fluid (IRF) and/or subretinal pigment epithelium (RPE) fluid with adjacent SRF/IRF following $>6$ months of monthly anti-VEGF treatment. Idiopathic polypoidal choroidal vasculopathy and central serous retinopathy cases were excluded. We excluded eyes with anti-VEGF therapy $<28$ days prior, photodynamic therapy (PDT) $<3$ months prior or $>4$ prior PDT treatments, significant subfoveal-fibrosis ( $>50 \%$ of lesion), prior triamcinolone
( $<6$ months), intraocular surgery ( $<2$ months), history of vitrectomy, active intraocular-inflammation, vitreous hemorrhage, subretinal hemorrhage involving $>1$ disc area of central fovea, previous RPE tear, or best-corrected visual acuity (BCVA) $<20 / 400$.

Each subject served as his/her own historical control and was treated by the same physician using identical retreatment criteria (before/after conversion).

Twenty-one eyes of 21 patients ( 9 males, 12 females; mean-age $80.7 \pm 4.5$ years) who had received $29.8 \pm 17.1$ (range 6-70) prior ranibizumab or bevacizumab injections over $31.6 \pm 17.4$ (range 7-63) months were a

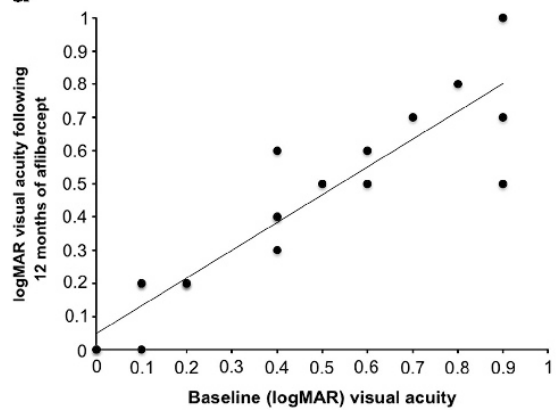

b

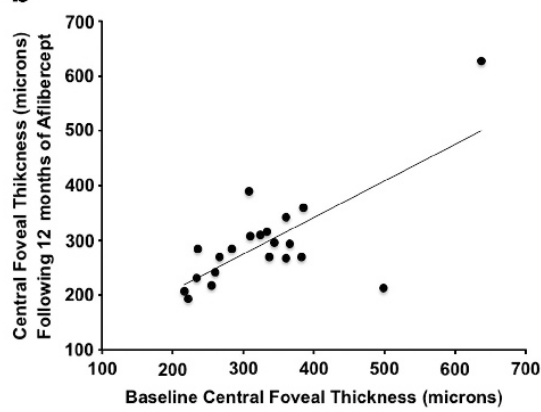

C

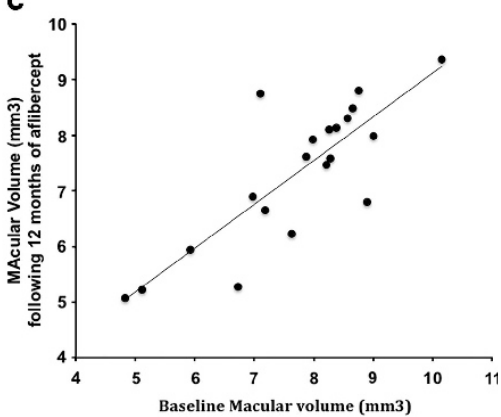

Figure 1 (a) Scatterplot showing a 12-month follow-up versus baseline logarithm of the minimal angle of resolution (logMAR) visual acuity after transitioning to aflibercept injections to treat recalcitrant neovascular age-related macular degeneration. (b) Scatterplot showing 12-month follow-up versus baseline central foveal thickness on SD-OCT (microns) after transitioning to aflibercept injections to treat recalcitrant neovascular age-related macular degeneration. (c) Scatterplot showing a 12-month follow-up versus baseline macular volume on SD-OCT $\left(\mathrm{mm}^{3}\right)$ after transitioning to aflibercept injections to treat recalcitrant neovascular age-related macular degeneration.

Table 1A Visual and anatomical outcomes after converting to aflibercept in the study population with refractory neovascular age-related macular degeneration $(n=21)$

\begin{tabular}{lcccccc}
\hline Parameter & $\begin{array}{c}\text { Baseline mean } \pm S D \\
(\text { range })\end{array}$ & $\begin{array}{c}1 \text { Month } \\
\text { mean } \pm S D(\text { range })\end{array}$ & $\begin{array}{c}3 \text { Months } \\
\text { mean } \pm S D(\text { range })\end{array}$ & $\begin{array}{c}6 \text { Months } \\
\text { mean } \pm S D(\text { range })\end{array}$ & $\begin{array}{c}12 \text { Months } \\
\text { mean } \pm S D(\text { range })\end{array}$ & $\begin{array}{c}\text { P-value } \\
\text { a }\end{array}$ \\
\hline BCVA (logMAR) & $0.42 \pm 28(0.1-0.90)$ & $0.39 \pm 0.30(0-1)$ & $0.39 \pm 0.31(0-1)$ & $0.42 \pm 0.28(0-0.83)$ & $0.40 \pm 0.28(0-1)$ & 0.48 \\
Central subfoveal & $329.38 \pm 102.67$ & $306.05 \pm 92.62$ & $332.14 \pm 101.70$ & $304.14 \pm 83.48$ & $294.7 \pm 91.35$ & 0.038 \\
thickness $(\mu \mathrm{m})$ & $(216-637)$ & $(200-608)$ & $(208-658)$ & $(206-609)$ & $(193-627)$ & $7.33 \pm 1.27$ \\
Macular volume $\left(\mathrm{mm}^{3}\right)$ & $7.71 \pm 1.32$ & $7.40 \pm 1.15$ & $7.75 \pm 1.27$ & $7.52 \pm 1.13$ & 0.033 \\
& $(4.83-10.15)$ & $(4.71-8.60)$ & $(4.92-9.32)$ & $(5.23-9.02)$ & $(5.07-9.36)$ \\
\hline
\end{tabular}

Abbreviations: BCVA, best-corrected visual acuity; $\log \mathrm{MAR}$, logarithm of minimal angle of resolution; PED, pigment epithelial detachment.

${ }^{\text {a }}$ Paired $t$-test, baseline compared with 12 months follow-up.

Table 1B Spectral domain optical coherence tomography analysis of pigment epithelial detachment after switching to aflibercept in eyes with refractory neovascular age-related macular degeneration $(n=15)$

\begin{tabular}{lcccc}
\hline Parameter & Baseline mean $\pm S D($ range) & 6 Months mean $\pm S D($ range) & 12 Months mean $\pm S D($ range) & P-value \\
\hline BCVA (logMAR) & $0.37 \pm 0.26(0.1-0.90)$ & $0.37 \pm 0.23(0-0.83)$ & $0.37 \pm 0.26(0-1)$ & 0.85 \\
PED Maximal Height $(\mu \mathrm{m})$ & $288.73 \pm 175.91(110-635)$ & $240.60 \pm 135.81(68-510)$ & $248.27 \pm 146.22(90-506)$ & 0.0019 \\
PED greatest basal diameter $(\mu \mathrm{m})$ & $2350.93 \pm 1067.58(457-4392)$ & $2075 \pm 1097.06(489-4470)$ & $1896.33 \pm 782.25(447-3528)$ & 0.029 \\
\hline
\end{tabular}

Abbreviations: BCVA, best-corrected visual acuity; $\log M A R, \operatorname{logarithm}$ of minimal angle of resolution; PED, pigment epithelial detachment. Maximal height is the distance between the outer border of Bruch's membrane and inner border of RPE.

${ }^{\text {a }}$ Paired $t$-test, baseline compared with 12 months follow-up. 
included. Average previous injections were 11.33/year (ranibizumab) and 11.1/year (bevacizumab). Nine patients were former smokers, while 12 had never smoked and none had prior myocardial infarction or cardiovascular accident. Five eyes (24\%) had received ranibizumab exclusively (mean, 27.4; range, 6-43) of which one patient had received a single prior PDT treatment, four eyes (19\%) had received bevacizumab exclusively (mean, 20.4; range 6-37), and 12 eyes (57\%) had been treated with both agents (mean, 33.8; range, 7-70 injections). Eyes had been treated with bevacizumab or ranibizumab monthly till signs of exudation were present. None of the eyes had vitreomacular traction or an epiretinal-membrane on baseline SD-OCT.

Patients received a minimum of three monthly aflibercept injections following which they switched to a bimonthly-interval if there was resolution of SRF/IRF, else were maintained on a monthly regimen. The interval frequency was guided by OCT.

At baseline, BCVA was $0.42 \pm 0.28$ logarithm of minimum-angle of resolution (logMAR) (20/52 snellen; range $0.10-0.90 \log \mathrm{MAR})$, central foveal thickness (CFT) was $329.38 \pm 102.67 \mu \mathrm{m}$ (range $216-637 \mu \mathrm{m}$ ) and macular volume (MV) was $7.71 \pm 1.32 \mathrm{~mm}^{3}$ (range $\left.4.83-10.15 \mathrm{~mm}^{3}\right)$.

After 12 months of aflibercept (mean 10.2 \pm 1.2 injections; range 10-12), BCVA was $0.40 \pm 0.28 \log \mathrm{MAR}$ (20/50 snellen; range $0-1, P=0.5$, Figure 1a), CFT decreased to $292.71 \pm 91.35 \mu \mathrm{m}$ (range 193-627, $P=0.038$, Figure $1 \mathrm{~b}$ ), and MV improved to $7.33 \pm 1.27 \mathrm{~mm}^{3}$ (range 5.07-9.36, $P=0.003$, Figure 1c; Table 1A). There was a reduction in proportion of eyes with persistent SRF $(17 / 21$ to $10 / 21, P=0.05)$ and IRF (10/21 to $5 / 21$ eyes, $P=0.2$ ). Figures 2 and 3 are representative case examples of the anatomical response after switching to aflibercept.
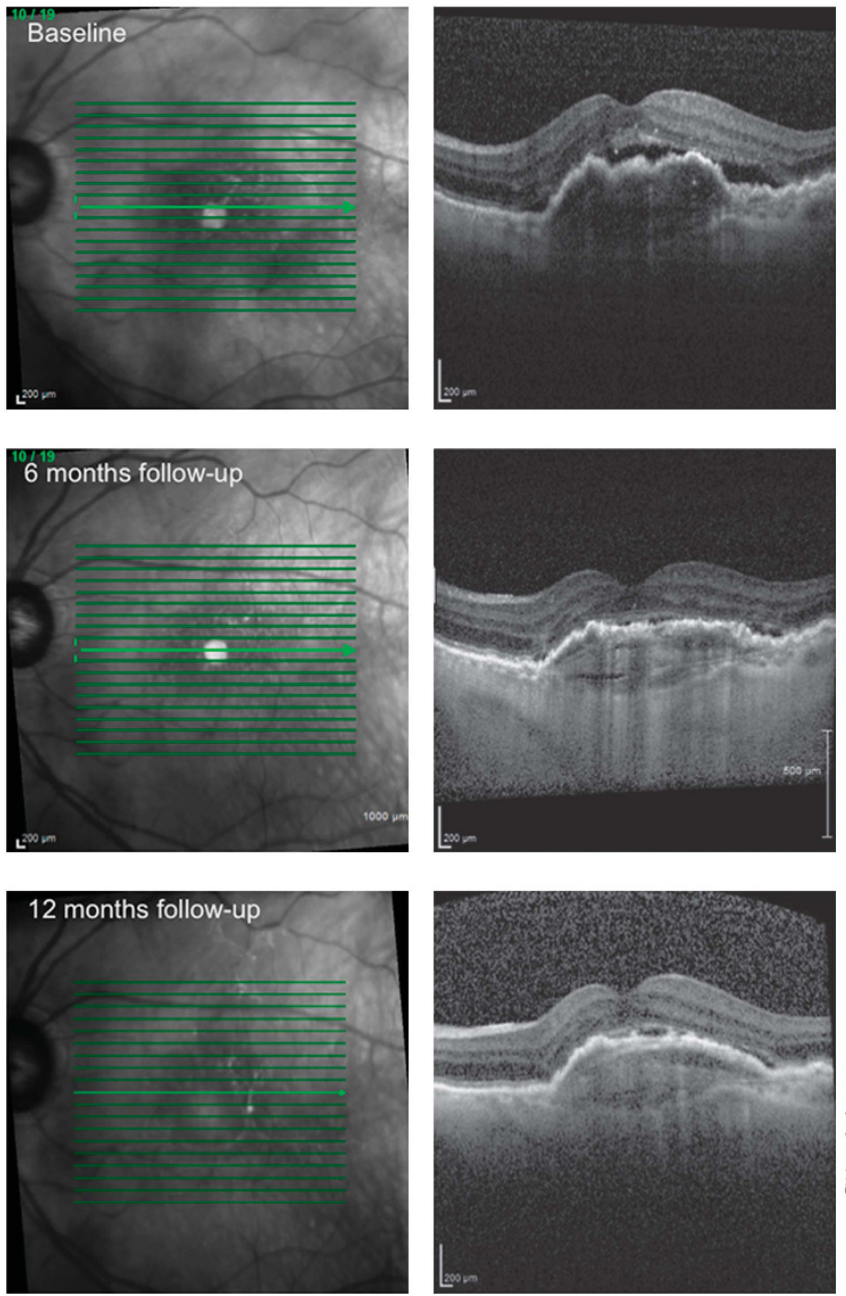

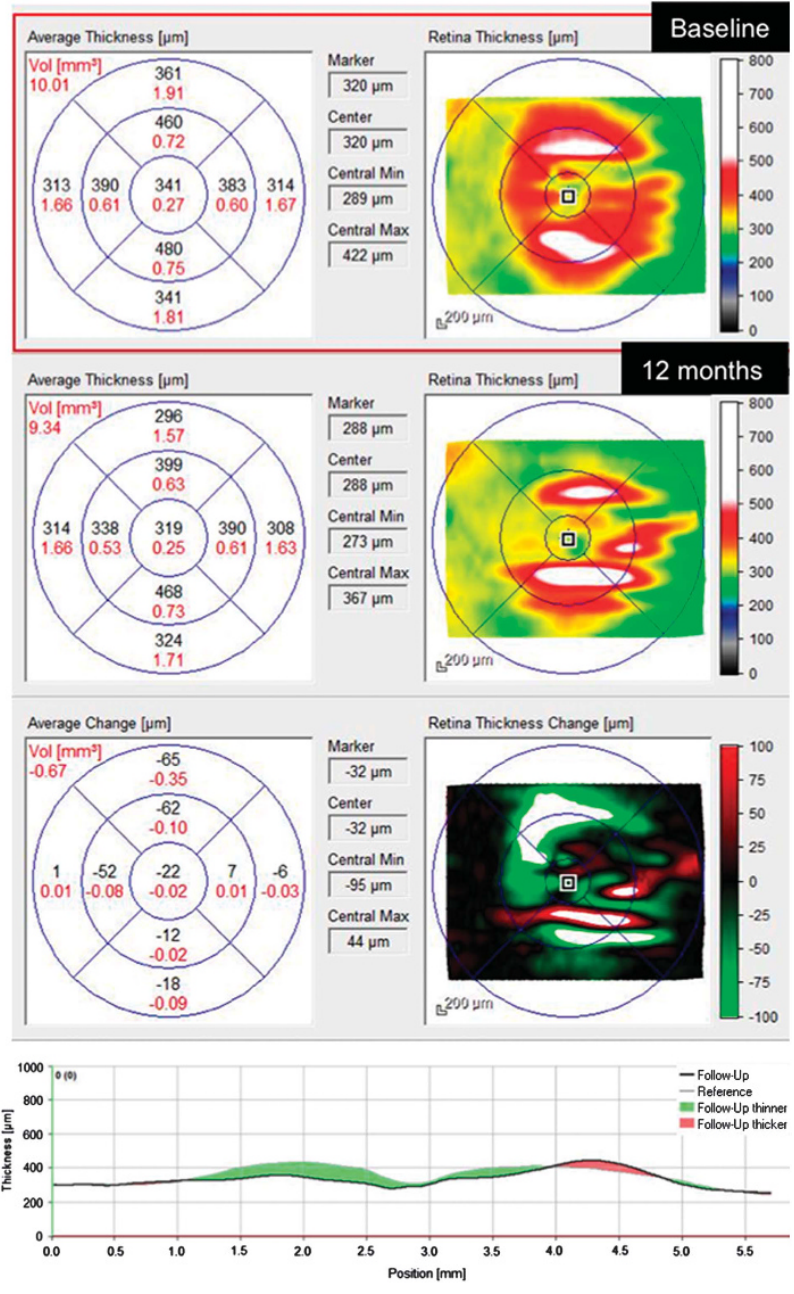

Figure 2 A patient with persistent SRF despite 22 prior anti-VEGF injections (1 Bevacizumab and 21 Ranibizumab) over the prior 22 months and was transitioned to aflibercept. Following 12 monthly aflibercept injections, SRF substantially reduced on SD-OCT. CFT improved from 341 to $319 \mu \mathrm{m}$ and macular volume reduced from 10.01 to $9.34 \mathrm{~mm}^{3}$. Visual acuity was preserved at $20 / 60$. 

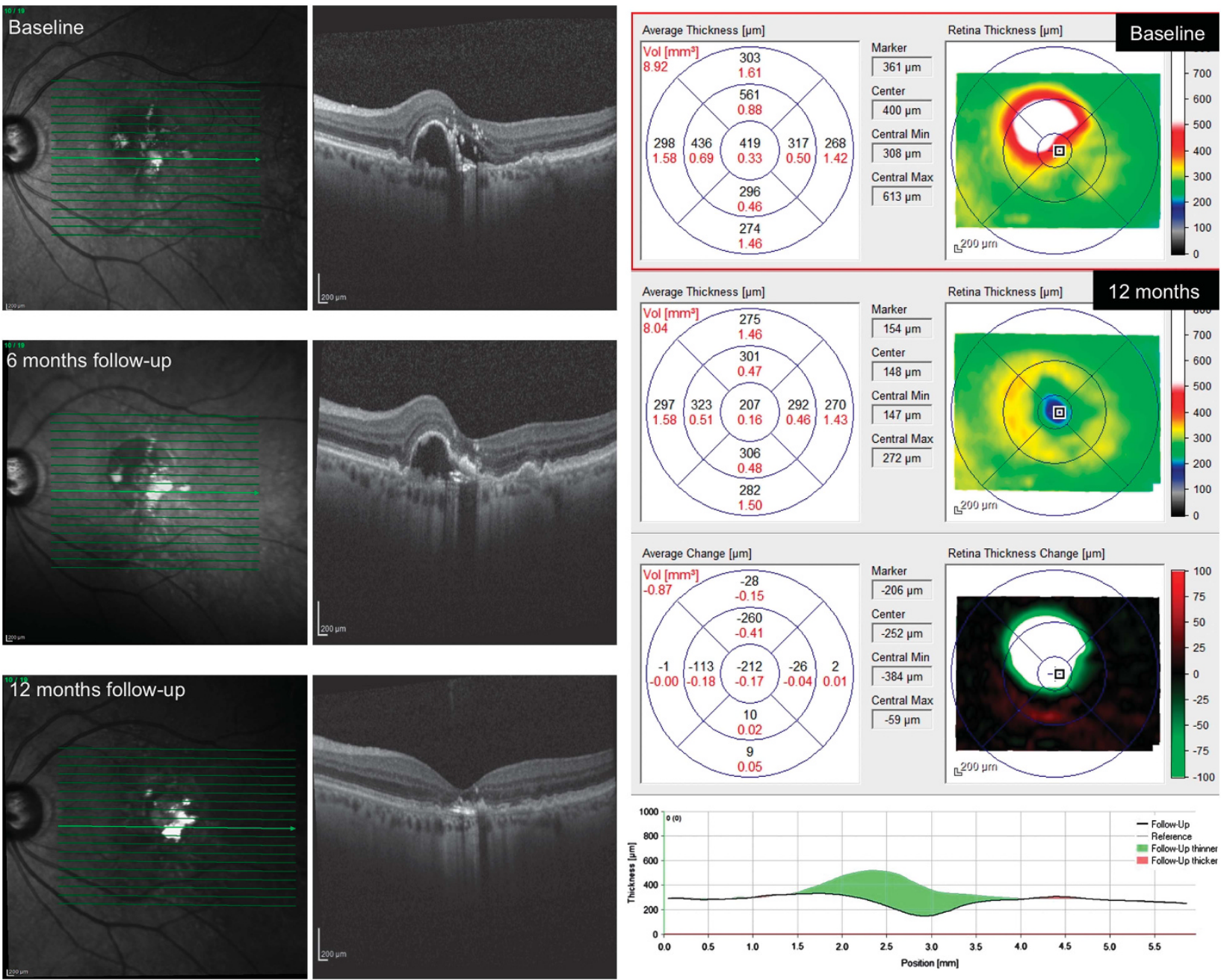

Figure 3 A patient with a persistent pigment epithelial detachment (PED) and SRF despite 45 prior ranibizumab injections over the prior 50 months, was transitioned to aflibercept. Following 12 monthly aflibercept injections, there was resolution of the PED and SRF on SD-OCT. CFT improved from 419 to $207 \mu \mathrm{m}$ and macular volume reduced from 8.92 to $8.94 \mathrm{~mm}^{3}$. Visual acuity was preserved at $20 / 60$.

We analyzed a subgroup of 15 eyes with a persistent fibrovascular or serous pigment epithelial detachment (PED). Using software calipers, we calculated a significant reduction of greatest basal diameter and maximal height both at 6 and 12 months (Table 1B). None of the eyes in our study developed significant ocular or systemic adverse events.

\section{Discussion}

Short-term efficacy of transitioning to aflibercept in such recalcitrant eyes has been reported. ${ }^{4-9}$ Potential explanations for the overall anatomic success of aflibercept therapy in recalcitrant eyes include tachyphylaxis, pharmacogenetics, or the increased binding affinity of aflibercept.

The anatomic gains in our study did not translate into improved visual acuity. This is not surprising, as our patients had received a mean of 29.8 prior injections with persistent exudation. Prior studies have shown that in cases of chronic AMD, conversion from bevacizumab to ranibizumab yielded improvements in anatomy, but not visual acuity. ${ }^{10}$

We did not analyze the characteristics of eyes that failed to respond to aflibercept. It is also not yet clear whether similar but earlier intervention with aflibercept could avoid visual acuity loss and whether cases initially unresponsive to aflibercept might show similar responses when switching to another anti-VEGF medication such as ranibizumab. Most patients required monthly aflibercept, more frequent than the bimonthly dosing it is designed for as these were recalcitrant eyes. It is also possible that as we included eyes that had been followed for 12 months on aflibercept, these were cases more responsive, as non-responders may have been switched to another regimen or might elect to abandon treatment. 
In conclusion, this study provides 1-year results following transition to aflibercept for previously treated eyes. We observed a significant reduction in CFT, MV, PED height, and diameter with a near $50 \%$ decrease in the number of eyes with persistent SRF/IRF.

\section{Summary}

What was known before

- In patients with recalcitrant AMD despite prior antiVEGF treatments, intravitreal aflibercept can result in anatomic improvement in the short term.

\section{What this study adds}

- In patients with recalcitrant AMD despite prior anti-VEGF treatments, intravitreal aflibercept leads to anatomic improvement at 12 months, reduction in proportion of eyes with SRF, and reduction in PED dimensions, while preserving visual acuity.

\section{Conflict of interest}

The authors declare no conflict of interest.

\section{Acknowledgements}

This work was supported in part by an unrestricted grant from Research to Prevent Blindness, NY.

\section{References}

1 Group CR, Martin DF, Maguire MG, Ying GS, Grunwald JE, Fine SL et al. Ranibizumab and bevacizumab for neovascular age-related macular degeneration. $N$ Engl J Med 2011; 364: 1897-1908.

2 Stewart MW, Rosenfeld PJ, Penha FM, Wang F, Yehoshua Z, Bueno-Lopez E et al. Pharmacokinetic rationale for dosing every 2 weeks versus 4 weeks with intravitreal ranibizumab, bevacizumab, and aflibercept (vascular endothelial growth factor Trap-eye). Retina 2012; 32: 434-457.

3 Ho VY, Yeh S, Olsen TW, Bergstrom CS, Yan J, Cribbs BE et al. Short-term outcomes of aflibercept for neovascular age-related macular degeneration in eyes previously treated with other vascular endothelial growth factor inhibitors. Am J Ophthalmol 2013; 156(1): 23-28.e2.

4 Bakall B, Folk JC, Boldt HC, Sohn EH, Stone EM, Russell SR et al. Aflibercept therapy for exudative age-related macular degeneration resistant to bevacizumab and ranibizumab. Am J Ophthalmol 2013; 156: 15-22. e11.

5 Yonekawa Y, Andreoli C, Miller JB, Loewenstein JT, Sobrin L, Eliott D et al. Conversion to aflibercept for chronic refractory or recurrent neovascular age-related macular degeneration. Am J Ophthalmol 2013; 156(1): 29-35.e2.

6 Cho H, Shah CP, Weber M, Heier JS. Aflibercept for exudative AMD with persistent fluid on ranibizumab and/or bevacizumab. Br J Ophthalmol 2013; 97: 1032-1035.

7 Patel KH, Chow CC, Rathod R, Mieler WF, Lim JI, Ulanski 2nd, LJ et al. Rapid response of retinal pigment epithelial detachments to intravitreal aflibercept in neovascular age-related macular degeneration refractory to bevacizumab and ranibizumab. Eye (Lond) 2013; 27: 663-668.

8 Kumar N, Marsiglia M, Mrejen S, Fung A. T, Slakter J, Sorenson $\mathrm{J}$ et al. Visual and anatomical outcomes of intravitreal aflibercept in eyes with persistent subfoveal fluid despite previous treatments with ranibizumab in patients with neovascular age-related macular degeneration. Retina 2013; 33: 1605-1612.

9 Chaikitmongkol V, Bressler NM. Dramatic resolution of choroidal neovascular abnormalities after single aflibercept injection following years of ranibizumab use. JAMA Ophthalmol 2013; 131: 260-262.

10 Ehlers JP, Spirn MJ, Shah CP, Fenton GL, Baker PS, Regillo CD et al. Ranibizumab for exudative age-related macular degeneration in eyes previously treated with alternative vascular endothelial growth factor inhibitors. Ophthalmic Surg Lasers Imaging 2010; 41: 182-189. 